\title{
Powder metallurgy processed metal-matrix friction materials for space applications
}

\author{
Yelong XIAO ${ }^{1}$, Pingping YAO ${ }^{1, *}$, Kunyang FAN ${ }^{1}$, Haibin ZHOU $^{1}$, Minwen DENG ${ }^{1}$, Zongxiang JIN ${ }^{2}$ \\ ${ }^{1}$ State Key Laboratory of Powder Metallurgy, Central South University, Changsha 410083, China \\ ${ }^{2}$ Shanghai Key Laboratory of Spacecraft Mechanism, Shanghai 201108, China \\ Received: 15 December 2016 / Revised: 10 March 2017 / Accepted: 05 June 2017 \\ C The author(s) 2017. This article is published with open access at Springerlink.com
}

\begin{abstract}
Owing to the increasing demand for tribological brakes for space applications, the development of novel materials and advanced technologies is necessary. This paper presents the design, characterization, and realization of powder metallurgy processed metal-matrix friction materials intended for the above-mentioned tribological brakes. Selecting appropriate ingredients, which provides an effective way to tailor the properties of the friction material, is evolving as a strategy to meet the design requirements. The tribological behaviors of the friction material are experimentally investigated under different conditions, and special attention is focused on the vacuum tribology. Examinations and analyses of the friction surface and subsurface corroborate the wear mechanism. In addition, the erosion resistances of the friction material are evaluated by exposure tests of ultraviolet irradiation and atomic oxygen. Finally, present and potential space applications of the friction material are also introduced based on experimental studies.
\end{abstract}

Keywords: friction \& wear; material designs; space application; irradiation; powder metallurgy

\section{Introduction}

The success of space missions depends critically on the reliability of space mechanisms and this in turn is dependent on the life and functionality of their component parts [1]. Space tribology is the management of friction and wear processes in those parts that have a tribological element, and focuses on anti-friction and anti-wear properties [2-4]. However, reports concerning tribological brakes that execute the braking operations, clutching operations, or overload protection of spacecraft or space mechanism are limited, especially in certain fields like friction materials.

Although tribological brakes represent only a tiny fraction of the spacecraft's cost, they are responsible for avoiding single-point failures that cripple or debilitate expensive spacecraft, such as brake failures for the docking mechanism determining the rendezvous and docking of spacecrafts. The purposes of brakes within the anticipated operational scenario are the following: precise velocity control; stable, limited, selectively controlled output frictional torque; long lifetime; and high reliability. In addition, unlike traditional brake systems, for space mechanisms only one brake should take on two or more of the aforementioned functions so as to reduce payload weight and size and, thus, the cost of missions.

The mechanical, environmental, and endurance requirements of space applications exceed the capabilities of available brake technology, resulting in a demand for novel materials and technologies that are more advanced. Lv et al. [5] fabricated carbon and aramid fibers reinforced polyimide composites for application in spacecrafts. Hawthorne et al. [6] demonstrated that polymeric and some ceramic materials exhibit low sliding friction. Some ceramicbased materials show stable friction characteristics, with low wear rates, and thus are potentially suitable

* Corresponding author: Pingping YAO, E-mail: yaopingpingxx@sohu.com 
for use in long-life space mechanisms such as the brakes in the space station remote manipulator system. Baker et al. [7] examined the tribological properties of a ceramic material for a brake intended for the European Robotic Arm (ERA) under different conditions. Unfortunately, the ceramic material is susceptible to non-linear and "dysfunctional" effects when subjected to testing in standard thermal and pressure environments.

In 2003, Central South University initiated and pioneered the study of novel friction materials for space applications in China [8-10]. Consequently, after eight years, a powder metallurgy processed metalmatrix friction material was used in the docking mechanism for the "Shenzhou" docking mission. In this paper, selected highlights of a fourteen-year study of powder metallurgy processed metal-matrix friction materials for space applications will be presented, particularly in the area of friction materials design.

\section{Experimental procedures and materials}

\subsection{Experimental procedures}

\subsubsection{Friction and wear test}

Friction and wear behaviors of metal-matrix friction materials were tested with a ring-on-ring braking test system (Fig. 1) which was equipped with a lowtemperature vacuum chamber. The friction pairs of the friction materials with $2 \mathrm{Cr} 13$ stainless steel (0.16-0.35 C, 12-14 Cr, $\leq 1.0 \mathrm{Si}, \leq 0.035 \mathrm{P}, \leq 0.03 \mathrm{~S}, \leq 1.0 \mathrm{Mn}$, and $\mathrm{Fe}$ balance, HRC $40 \pm 2$ ) as counterparts were machined into rings with an $80 \mathrm{~mm}$ outer diameter and a $50 \mathrm{~mm}$ inner diameter. The counterpart surface was tumbled to a mean surface roughness, $R_{\mathrm{a}}$ of $0.2 \mu \mathrm{m}$.

The tests were performed by accelerating the rotation shaft with the counterpart ring to the desired rotational speed. When this speed was attained, the motor power was switched off and the friction ring was loaded closely against the counterpart ring at a desired normal pressure until the rotation shaft completely stopped rotating. This test was repeated 10 times for each specimen. This test system was equipped with a computerized data acquisition and control system for controlling and monitoring of various parameters. The test parameters are given in Table 1.

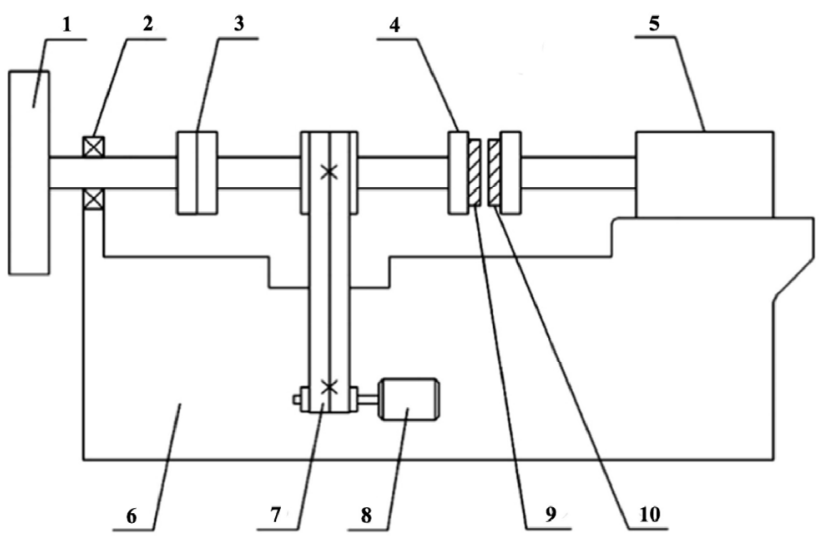

Fig. 1 A schematic diagram of the ring-on-ring braking test system: 1-flywheel, 2-bearing, 3-clutch, 4-rotation shaft, 5-air cylinder, 6-concrete base, 7-feed belt, 8-motor, 9-counterpart ring, 10 -friction ring.

Table 1 Test parameters employed in wear tests.

\begin{tabular}{cc}
\hline Parameters & Values \\
\hline Rotational speed $(\mathrm{rpm})$ & 3000 \\
Nominal contact pressure $(\mathrm{MPa})$ & $0.016,0.032,0.048$, and 0.064 \\
Vacuum pressure $(\mathrm{Pa})$ & $1 \times 10^{0}-1 \times 10^{-2}$, and $1 \times 10^{-3}$ \\
& Room temperature $(25)$, \\
Temperature $\left({ }^{\circ} \mathrm{C}\right)$ & $0,-20$, and -40 \\
\hline
\end{tabular}

During each test period, the instantaneous friction coefficient $(\mu)$ can be calculated as

$$
\mu=\frac{2 M}{F_{\mathrm{a}}\left(r_{0}+r_{\mathrm{i}}\right)}
$$

where $M$ is the measured frictional torque, $r_{0}$ is the half outer diameter of rings, $r_{\mathrm{i}}$ is the half inner diameter of rings, and $F_{\mathrm{a}}$ is the normal force.

The mean friction coefficient $\left(\mu_{\text {mean }}\right)$ is defined as

$$
\mu_{\text {mean }}=\frac{1}{\left(t_{1}-t_{c}\right)} \int_{t_{c}}^{t_{1}} \mu(\tau) \mathrm{d} \tau
$$

where $t_{1}$ is the lock-up time (rotational speed $=0$ ), $t_{\mathrm{c}}$ is the time at which rings are brought in contact, and $\mu(t)$ is the instantaneous friction coefficient.

The frictional stability (FS) is defined as

$$
\mathrm{FS}=\frac{\mu_{\text {mean }}}{\mu_{\text {max }}}
$$

where $\mu_{\max }$ is the maximum friction coefficient.

During wear tests, the wear rate $(\omega)$ is defined as 


$$
\omega=\frac{m_{0}-m_{\mathrm{i}}}{n}
$$

where $m_{0}$ is the weight of friction rings before wear tests, $m_{\mathrm{i}}$ is the weight of friction rings after wear tests, and $n$ is the number of cycles.

The amount of wear was determined by weighing friction rings before and after wear tests using a precision electronic balance with an accuracy of $0.001 \mathrm{~g}$. The morphologies of the friction surface and subsurface were observed using scanning electron microscopy (SEM).

\subsubsection{Equipment to evaluate brakes for space applications}

The tribological performances of the brakes for space applications were evaluated using a multi-disc clutch brake system at the Shanghai Key Laboratory of Spacecraft Mechanism. The brake system was mounted inside a special ground simulation system which was equipped with temperature control in a range between $-120{ }^{\circ} \mathrm{C}$ and $+180{ }^{\circ} \mathrm{C}$ and could be evacuated to a residual pressure of $1 \times 10^{-5} \mathrm{~Pa}$.

In this study, the ground simulation testing procedure we have proposed is the same as that published in our previous work [9], and will not be described in detail here. The frictional torque of the brakes was measured with a torque sensor, and the data was automatically sent for processing to a computer.

\subsubsection{Irradiation test}

Atomic oxygen (AO) and ultraviolet irradiation (UV) experiments were carried out in ground simulation facilities under a vacuum environment $\left(1 \times 10^{-3} \mathrm{~Pa}\right)$. $\mathrm{AO}$ irradiation was performed by impingement with a mean translational kinetic energy of $5 \mathrm{eV}$ and flux of $5.2 \times 10^{15}$ atoms $\cdot \mathrm{cm}^{-2} \cdot \mathrm{s}^{-1}$. This is equal to the impact energy of $\mathrm{AO}$ on the surfaces of spacecraft in the actual low earth orbit (LEO) space environment. The exposure period was controlled at $480 \mathrm{~min}$. UV irradiation was performed with a wavelength range of 115-400 nm and the energy flux was determined to be about six fold that of the solar constant. The exposure period was controlled at $600 \mathrm{~min}$, being equivalent to 60 sun hours. In $\mathrm{AO} / \mathrm{UV}$ combining irradiation experiments, samples were irradiated firstly by $\mathrm{AO}$, and then by UV.

During irradiation tests, the mass loss rate $(\Delta m)$ is defined as

$$
\Delta m=\frac{m-m_{1}}{S}
$$

where $m$ is the weight of samples before irradiation tests, $m_{1}$ is the weight of samples after irradiation tests, and $S$ is the irradiated area. The mass loss was determined by weighing samples before and after irradiation tests using a precision electronic balance with an accuracy of $0.001 \mathrm{~g}$.

\subsection{Materials design issues}

Metal-matrix friction composites can be defined as a metallic matrix (usually an alloy of $\mathrm{Cu}, \mathrm{Fe}$, or $\mathrm{Ni}$ ) containing lubricant components and friction components. Due to their excellent tribological properties and adaptability to working conditions, those materials fabricated via powder metallurgy route hold great promise for space applications. The properties of the composites can be tailored by selecting appropriate constituents in order to meet the design requirements.

\subsubsection{Metal matrix}

The metallic constituents employed in the friction material provide strength, high temperature stability, oxidation resistance, and high thermal conductivity [11]. Generally, the contents of the metal matrix should be controlled in the range of $40-80 \mathrm{wt} \%$. Copper and iron have been found to be promising candidates for practical use as the matrix phase. In order to determine the preferable matrix, the total amount of $\mathrm{Cu}$ and $\mathrm{Fe}$ in this study was $70 \mathrm{wt} \%$. Different weight fractions of $\mathrm{Cu}$ were added in the range of $0 \mathrm{wt} \%, 10 \mathrm{wt} \%$, $20 \mathrm{wt} \%, 30 \mathrm{wt} \%, 40 \mathrm{wt} \%, 50 \mathrm{wt} \%, 60 \mathrm{wt} \%$, and $70 \mathrm{wt} \%$. Thus, the additions of Fe were correspondingly in the range of $70 w t \%, 60 w t \%, 50 w t \%, 40 w t \%, 30 w t \%$, $20 \mathrm{wt} \%, 10 \mathrm{wt} \%$, and $0 \mathrm{wt} \%$, respectively. The contents of other ingredients were fixed (5-7 wt $\%$ Sn, 5-7 wt \% graphite, 6-8 wt $\% \mathrm{MoS}_{2}, 5-7 \mathrm{wt} \% \mathrm{SiO}_{2}, 4-8 \mathrm{wt} \%$ others).

Figure 2(a) shows $\mu_{\text {mean }}$ and FS as a function of $\mathrm{Cu}$ content. A significant decrease was observed in the $\mu_{\text {mean }}$ values with an increase in $\mathrm{Cu}$ content up to $30 \mathrm{wt} \%$ after which a slightly decreasing trend was observed. Vibrations created by brakes are often harmful during space operations. Steady operations 

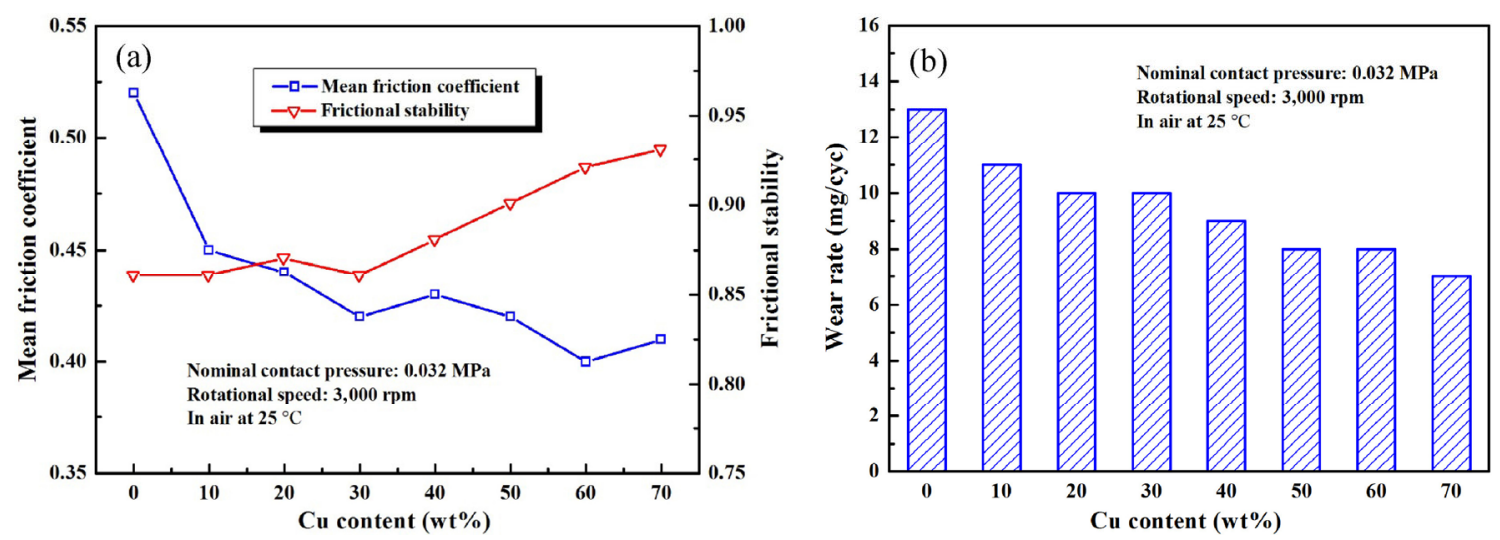

Fig. 2 Variations of (a) $\mu_{\text {mean }}$ and FS, and (b) wear rate with $\mathrm{Cu}$ content.

and lower vibration depend on FS. The greater the FS, the steadier and lower the vibrations. The FS was low and stable at $\mathrm{Cu}$ contents below $30 \mathrm{wt} \%$ and then increased at $\mathrm{Cu}$ contents above $30 \mathrm{wt} \%$. The effects of $\mathrm{Cu}$ content on the wear rate are summarized in Fig. 2(b). With increasing $\mathrm{Cu}$ content, the wear rate reduced significantly.

The strength and hardness of Fe are higher than those of $\mathrm{Cu}$, so the hard $\mathrm{Fe}$ particles resisted the microcutting actions of the counterpart and abrasives more effectively during the course of friction. Simultaneously, the accumulation of Fe particles removed from the friction material on the surface enhanced the friction resistance between two contacting surfaces. Secondly, compared with $\mathrm{Cu}$, Fe was more prone to adhering to the steel counterpart, so Fe particles tended to weld with the counterpart under the influences of the applied load and frictional heat [12]. This resulted in the increase in the friction coefficient, the decrease in FS, and the increase in the wear rate. Thirdly, $\mathrm{Cu}$ dissipated frictional heat more effectively, so it can improve the tribological properties owing to the superior thermal conductivity. Hence, copper was selected to be the metal matrix. Furthermore, the addition of $\mathrm{Sn}$ to materials contributed to improve the strength and hardness of the copper matrix.

\subsubsection{Lubricant components}

Lubricants like graphite or $\mathrm{MoS}_{2}$ impart smoother and vibration less engagement during the course of friction, and also provide anti-seizure characteristics and enhance wear resistance [13]. The combined effects of graphite and $\mathrm{MoS}_{2}$ on the tribological properties were evaluated. The total amount of graphite and $\mathrm{MoS}_{2}$ in this study was $12 \mathrm{wt} \%$. Different weight fractions of graphite, in the range of $12 \mathrm{wt} \%, 10 \mathrm{wt} \%$, $8 \mathrm{wt} \%, 6 \mathrm{wt} \%, 4 \mathrm{wt} \%, 2 \%$, and $0 \mathrm{wt} \%$, were added. The respective amounts of $\mathrm{MoS}_{2}$ added were $0 \mathrm{wt} \%$, $2 \mathrm{wt} \%, 4 \mathrm{wt} \%, 6 \mathrm{wt} \%, 8 \mathrm{wt} \%, 10 \mathrm{wt} \%$, and $12 \mathrm{wt} \%$. The contents of other ingredients were fixed (43-60 wt\% $\mathrm{Cu}, 5-7 \mathrm{wt} \% \mathrm{Sn}, 5-8 \mathrm{wt} \% \mathrm{Fe}, 5-7 \mathrm{wt} \% \mathrm{SiO}_{2}, 5-7 \mathrm{wt} \%$ $\mathrm{CaCO}_{3}, 8-12 \mathrm{wt} \%$ others).

Figure 3(a) presents the variations of $\mu_{\text {mean }}$ and FS with the mass ratio of graphite to $\mathrm{MoS}_{2} \cdot \mu_{\text {mean }}$ was almost unchanged with an increase in the mass ratio up to $6: 6$, and then promptly increased and rapidly reached a relatively stable value at the mass ratio above 6:6. FS was almost insensitive to the change of graphite and $\mathrm{MoS}_{2}$ content. As shown in Fig. 3(b), the wear rate slightly increased with increasing the mass ratio to $8: 4$ and reached the lowest value when the mass ratio was $6: 6$, and then significantly increased with increasing the mass ratio.

In our previous work [8], it was found that solid-solid phase reactions occurred between $\mathrm{MoS}_{2}$ and other constituents in the sintering process. The reaction products were complicated $\mathrm{Mo}_{2} \mathrm{C}, \mathrm{Cu}_{10.98} \mathrm{Mo}_{18} \mathrm{~S}_{24}, \mathrm{Cu}_{7} \mathrm{~S}_{4}$, and $\mathrm{CaMoO}_{4}$. Just like graphite and $\mathrm{MoS}_{2}, \mathrm{Cu}_{10.98} \mathrm{Mo}_{18} \mathrm{~S}_{24}$, and $\mathrm{Cu}_{7} \mathrm{~S}_{4}$ acting as lubricants were responsible for the desired effect of friction force stabilization. $\mathrm{Mo}_{2} \mathrm{C}$ and $\mathrm{CaMoO}_{4}$ were homogeneously embedded in the matrix, and acted as abrasives resulting in dispersion strengthening and could enhance the friction resistance and improve the wear-resistance to some extent. Nevertheless, as a result of the production of new 

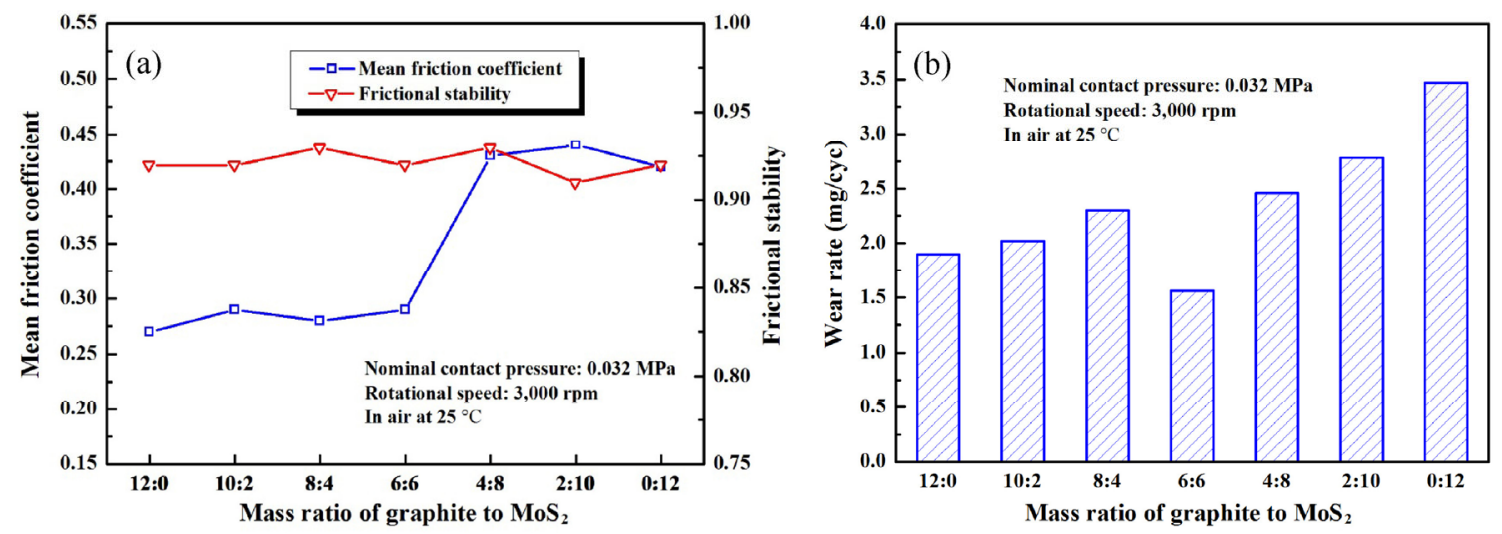

Fig. 3 Variations of (a) $\mu_{\text {mean }}$ and FS, and (b) wear rate with mass ratio of graphite to $\mathrm{MoS}_{2}$.

compounds, the abrasive level increased with increasing $\mathrm{MoS}_{2}$ content, the hardness of materials ascended, while compression strength descended, resulting in the increase in the friction coefficient and wear rate. However, there was an equilibrium mass of lubricant and abrasive that was achieved by tailoring the mass ratio of graphite to $\mathrm{MoS}_{2}$, at which point (i.e., a mass ratio was 6:6) the friction material attained outstanding comprehensive properties.

\subsubsection{Friction components}

Abrasives, such as $\mathrm{SiO}_{2}, \mathrm{SiC}$, or mullite are used to provide the desired friction coefficient and protect against the negative effects of lubricants [11]. The effects of $\mathrm{SiO}_{2}$ content on the friction and wear behaviors were studied. The total amount of $\mathrm{SiO}_{2}$ and $\mathrm{Cu}$ in this study was $60 \mathrm{wt} \%$. Different weight fractions of $\mathrm{SiO}_{2}$, in the range of $0 \mathrm{wt} \%, 2 \mathrm{wt} \%, 4 \mathrm{wt} \%, 6 \mathrm{wt} \%$, $8 \mathrm{wt} \%, 10 \mathrm{wt} \%$, and $12 \mathrm{wt} \%$, were added. Thus, the additions of $\mathrm{Cu}$ were correspondingly in the range of
$60 \mathrm{wt}^{2} \%, 58 \mathrm{wt} \%, 56 \mathrm{wt} \%, 54 \mathrm{wt} \%, 52 \mathrm{wt} \%, 50 \mathrm{wt} \%$, and $48 \%$. The contents of other ingredients were fixed (5-7 wt $\%$ Sn, 5-8 wt $\%$ Fe, 5-7 wt \% graphite, 6-8 wt $\%$ $\mathrm{MoS}_{2}, 3-5 \mathrm{wt} \% \mathrm{Al}_{2} \mathrm{O}_{3}, 6-10 \mathrm{wt} \%$ others).

Figure 4(a) presents $\mu_{\text {mean }}$ and FS as a function of the $\mathrm{SiO}_{2}$ weight fraction. $\mu_{\text {mean }}$ was noticeably enhanced by the addition of $\mathrm{SiO}_{2}$ into the friction formulations. A significant increase occurred in FS upon increasing $\mathrm{SiO}_{2}$ content up to $6 \mathrm{wt} \%$ after which a slight decreasing trend was observed. The influences of $\mathrm{SiO}_{2}$ content on the wear rate are shown in Fig. 4(b). The wear rate decreased upon decreasing $\mathrm{SiO}_{2}$ content to below $6 \mathrm{wt} \%$ and then increased at $\mathrm{SiO}_{2}$ concentrations above $6 \mathrm{wt} \%$.

Due to its high strength and hardness, $\mathrm{SiO}_{2}$ prevented the movement between two friction surfaces resulting in a higher friction coefficient. The amount of hard inclusions penetrating the friction layer obviously increased with increasing $\mathrm{SiO}_{2}$ content, so the friction coefficient correspondingly increased.
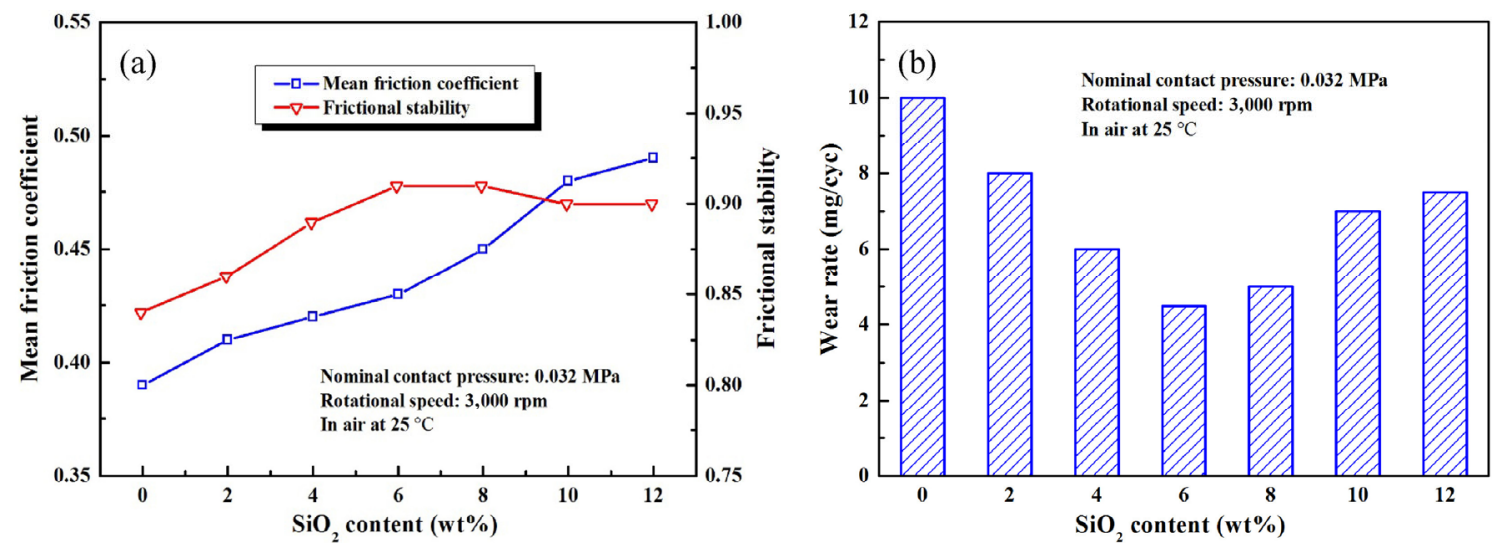

Fig. 4 Variations of (a) $\mu_{\text {mean }}$ and FS, and (b) wear rate with $\mathrm{SiO}_{2}$ content. 
Simultaneously, the broken and crushed $\mathrm{SiO}_{2}$ particles exfoliated from the friction material brought about particle abrasion and eliminated adhesive wear resulting in improved frictional stability. Ceramic reinforcements in the form of particulates were widely incorporated in soft and ductile materials like copper to relieve the extent of wear deformation in the subsurface region. Consequently, the wear resistance of the friction material was considerably improved [14]. $\mathrm{SiO}_{2}$ particulate could not react with the matrix and formed a weak bond with the matrix due to the slight wettability [12]. Therefore, the mechanical properties of the friction material dramatically deteriorated with $\mathrm{SiO}_{2}$ content in excess of $6 \mathrm{wt} \%$, leading to deterioration of the wear resistance.

Based on the above results, the chemical compositions of metal-matrix friction materials whose properties were tested under different conditions in sections below were obtained, as shown in Table 2 . Friction materials were made by a powder metallurgy process that involved powder processing, pressure compaction, and pressure sintering. The source powders were weighed with the given proportion, mixed in a V-type mixer for 6-8 h and then cold compacted under a pressure of 350-500 MPa. The green compacts placed on the steel backing plates were sintered at $780-850{ }^{\circ} \mathrm{C}$ with a pressure of $1.5-2.5 \mathrm{MPa}$ in a bell furnace saturated with hydrogen.

Table 2 Chemical compositions of metal-matrix friction materials. Element $\mathrm{Cu}$ Sn Fe Graphite $\mathrm{MoS}_{2} \mathrm{SiO}_{2} \mathrm{CaCO}_{3} \mathrm{Al}_{2} \mathrm{O}_{3}$ Others

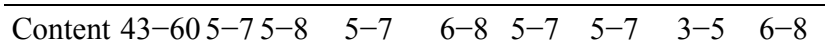
$(\mathrm{wt} \%)$

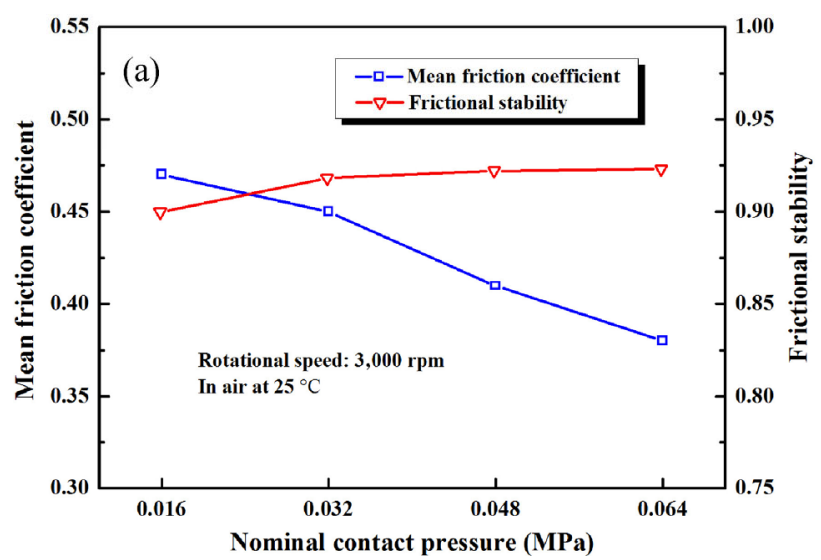

\section{Experimental results}

\subsection{Effects of nominal contact pressure on tribological properties}

Figure 5(a) shows the influences of changes in the nominal contact pressure on $\mu_{\text {mean }}$ and FS. $\mu_{\text {mean }}$ significantly decreased with the increase of the nominal contact pressure, whereas FS slightly increased with the increase in the nominal pressure. The relationship between the nominal contact pressure and the wear rate is shown in Fig. 5(b). There was a slight increase in the wear rate with increasing nominal contact pressure up to $0.048 \mathrm{MPa}$ after which a decreasing trend was observed.

The sliding movement occurred in very small areas at the asperities over time. The ruptures or breaks at the asperities and lubricants removed from the friction material brought about the generation of wear debris and friction layer, resulting in the steady-state friction characteristics and the decrease in the friction coefficient.

An increase in the load led to an increase in the wear rate. The wear behavior was attributed to the formation of the friction layers, mainly on the friction material. The friction force due to the ploughing action between the surfaces increased the temperature and broke the friction layers, resulting in an increase in the strength of the connections and metallic contact between the surfaces. This effect resulted in adhesion and increased the deformation at the surface layers, leading to further loss of the friction material. However, above that critical load, the accumulation

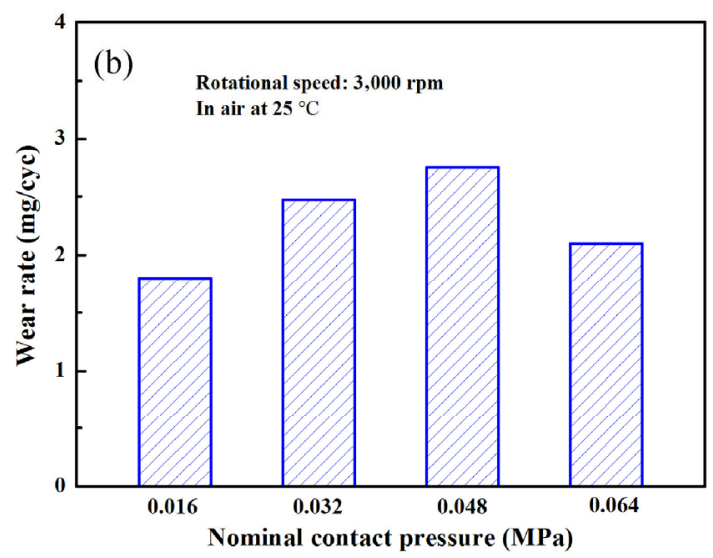

Fig. 5 Variations of (a) $\mu_{\text {mean }}$ and FS, and (b) wear rate with nominal contact pressure. 
and compaction of wear debris and some constituents exfoliated from the friction material gave rise to the generation of a thicker and denser surface layer, providing wear protection [8].

\subsection{Effects of vacuum pressure on tribological properties}

Figure 6(a) shows the effects of varying vacuum levels on $\mu_{\text {mean }}$ and FS. In comparison with those in low vacuum, the friction material in air exhibited a higher friction coefficient and lower frictional stability, whereas the friction coefficient was slightly lower and the frictional stability was almost unchanged in high vacuum. The wear rate of the friction material under different vacuum pressures is summarized in Fig. 6(b). A significant increase in the wear rate in vacuum compared with that in air was observed.

The composition of the surface layer formed on the friction material was found to have a strong influence on the frictional response. At the friction speed of 3,000 rpm, a large quantity of frictional heat was generated during the course of friction. Frictional heat could lead to sufficiently high surface temperature that resulted in relatively thick oxides on the contacting surfaces in air. The oxide layer with hard particles and wear debris plowed the counterface, and as mentioned in the previous subsection, the fracture of the oxide layer was observed. This caused increased wear due to spalling of the oxide layer and more metallic contact between the interacting surfaces, resulting in a corresponding increase in the $\mu_{\text {mean }}$ and wear rate. In vacuum, it was difficult to regenerate the adsorbed film and oxide layer. Wear debris dispersed in the course of milling and accumulated continually on the surface, forming a surface layer. The surface layer was rich in graphite and metal sulfides. The solid lubricant-rich layer, which provided improved wear resistance, stability, and reduced the friction coefficient could be produced between contact surfaces [8, 15].

On the other hand, in terms of the theory proposed by Bowden and Tabor, the friction resistance is derived from the formation of cold-weld junctions between surfaces $[16,17]$. By assuming that all micro-contacts are plastically deformed and the stress is equal to the penetration hardness, $\sigma_{0}$, of the material, the friction coefficient can be written as

$$
\mu=\frac{\tau_{\mathrm{c}}}{\sigma_{0}}
$$

$\sigma_{0}$ is a constant of the selected material, so the friction coefficient is determined by the shear strength $\tau_{\mathrm{c}}$ of the surface layer. The shear strength of oxide layer is greater than that of the friction layer in the presence of softer inclusions [17]. Hence, the friction coefficient of the friction material in air was higher than that in vacuum.

\subsection{Effects of ambient temperature on tribological properties}

The space environment differs greatly from that on earth, as it contains a high vacuum, temperature that fluctuates from -120 to $150{ }^{\circ} \mathrm{C}$ due to the influence of sunlight, and harsh space irradiation [2]. Due to the susceptibility to cold-shortness, metal-metal pairs are
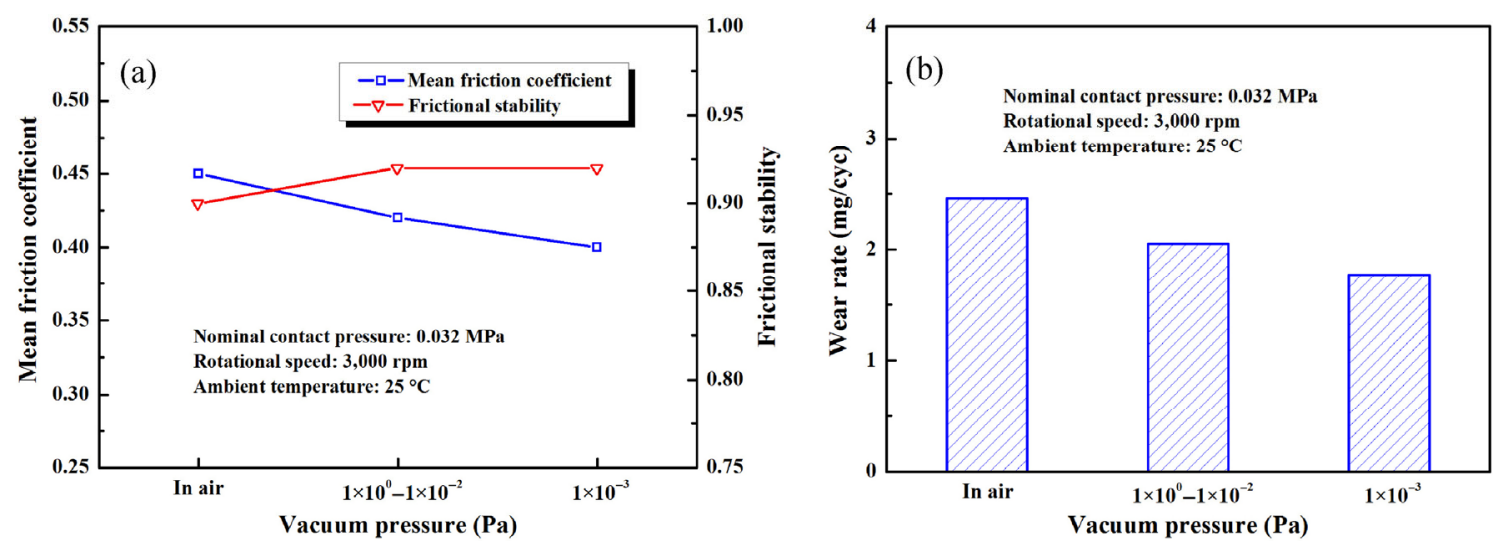

Fig. 6 Variations of (a) $\mu_{\text {mean }}$ and FS, and (b) wear rate with vacuum pressure. 
seldom used at cryogenic temperatures [18]. Therefore, it is fundamentally important to investigate the effect of low temperature on the friction behaviors of the friction material.

Figure 7 shows the variations of $\mu_{\text {mean }}$ and FS with ambient temperature in vacuum. $\mu_{\text {mean }}$ was almost insensitive to the ambient temperature. Certain differences in FS are presented at different ambient temperatures. Nonetheless, the values of FS exceeded 0.9. This implies that the friction material exhibited the excellent tribological properties in a certain temperature range. During the friction process, the friction material containing high contents of nonmetallic constituents could overcome the drawbacks of adhesion, cold-welding, and cold-shortness in high vacuum at a low temperature [8].

\subsection{Wear mechanism}

In air, due to the sufficient frictional heat, the continuous supply of $\mathrm{O}$ and occurrence of the tribo-oxidation promoted the formation of oxides during the friction process. The oxide layers were prone to spalling at low applied loads, whereas, the surface layers were formed and developed by trapping and compacting oxides, wear debris, and the powder on the constituents at certain applied loads. In addition, since the metal matrix wrapped up high contents of non-metallic ingredients it reduced the adhesive wear, cold-welding, and cold-shortness to a large extent.

As illustrated in Fig. 8, during the friction process, the hard three-body abrasives and peak asperities of the steel counterpart penetrated into the surface

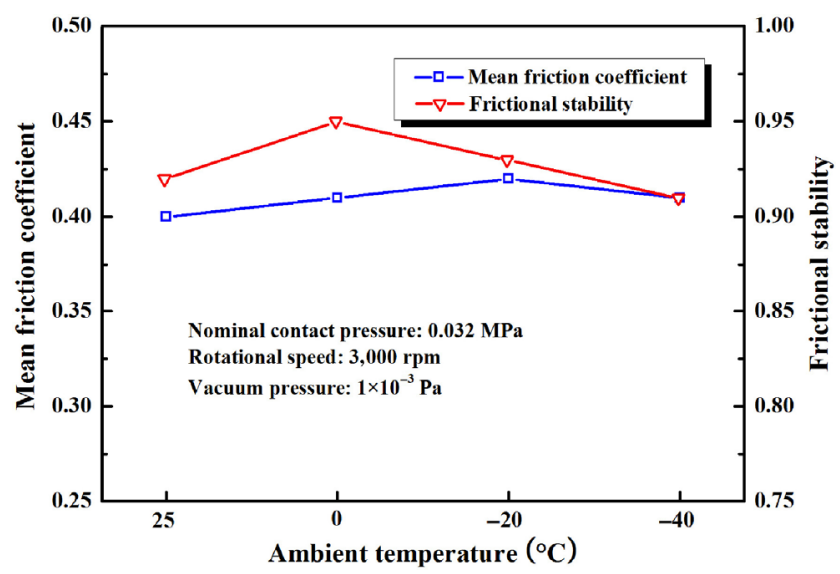

Fig. 7 Variations of $\mu_{\text {mean }}$ and FS with ambient temperature.

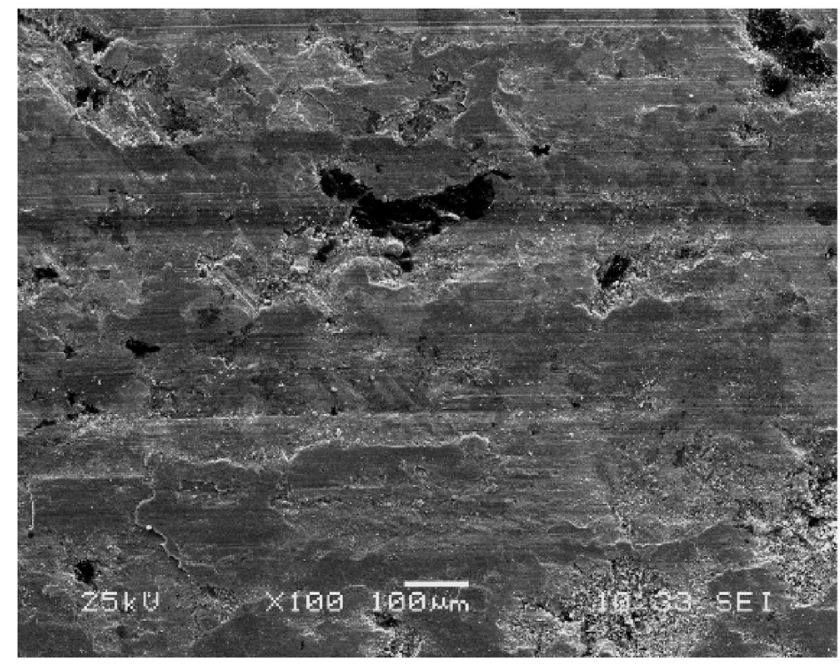

Fig. 8 SEM micrograph showing the worn surface with a number of furrows.

layer. Furrows were generated on the worn surface under the synergistic effects of normal pressure, the tangential stress, and frictional heat. This process is a manifestation of abrasive wear mechanisms.

As the friction process proceeded, subsurface microcracks were generated as seen in Fig. 9(b) due to the cyclic-plastic deformation. The microcracks then propagated to the worn surface where pits and spallation were found, as shown in Fig. 9(a). The fatigue wear was operative.

\subsection{AO and UV erosion resistance}

Table 3 presents mass loss rates of the friction material irradiated with atomic oxygen and ultraviolet rays, as well as their synergistic effects. During single AO exposure, a mass gain was detected, whereas mass loss was found upon exposures to single UV and $\mathrm{AO}+\mathrm{UV}$ irradiation. It can also be seen that in $\mathrm{AO}+\mathrm{UV}$ exposure, the mass loss was greater than that in single UV exposure. The mechanical bonding interface was formed among constituents of the friction material. In UV exposure, UV radiation might break those mechanical bonds with low binding energy and result in mass loss. In AO exposure, the friction material interacted with the incident $\mathrm{AO}$ beam, and the metalmatrix might be oxidized by interaction with oxygen atoms, resulting in the formation of a stable chemical reaction film on the surface. However, in $\mathrm{AO}+\mathrm{UV}$ exposure, UV radiation might break bonds between the 

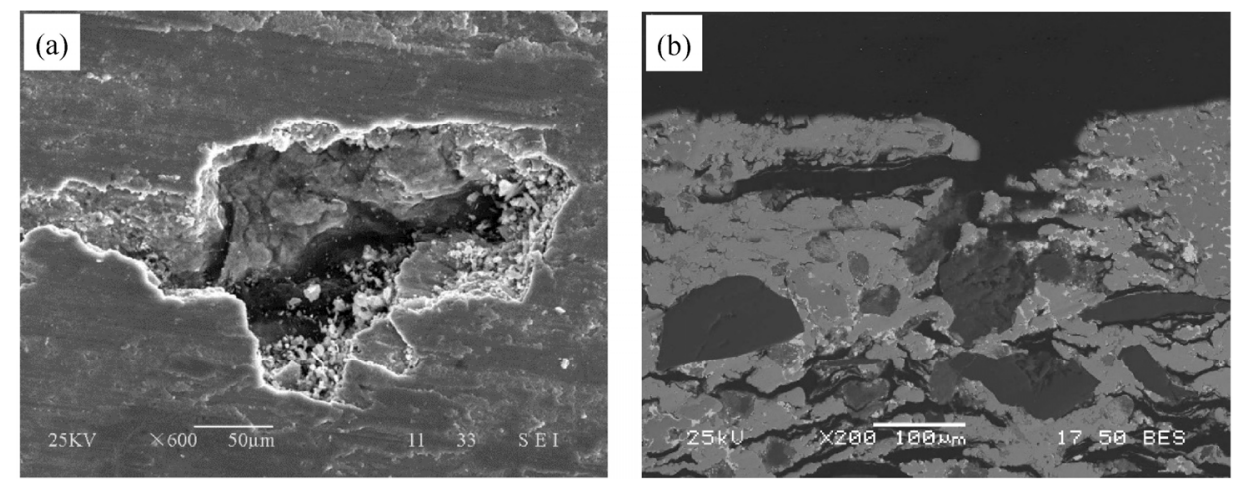

Fig. 9 SEM observations of (a) the worn surface and (b) the subsurface.

Table 3 Mass changes of the friction material under different exposure conditions.

\begin{tabular}{cc}
\hline Irradiations & Mass loss rate $\left(\mathrm{mg} / \mathrm{cm}^{2}\right)$ \\
\hline AO & -0.17 \\
$\mathrm{UV}$ & 0.22 \\
$\mathrm{AO}+\mathrm{UV}$ & 0.35 \\
\hline
\end{tabular}

chemical reaction film and the matrix, and accelerate the process of AO erosion. However, the results show that irradiations caused no significant mass loss of the friction material.

\section{Present and potential applications}

For reliably connecting and disconnecting two spacecrafts, the docking mechanism (Fig. 10(b)) has to provide shock absorption upon initial contact. The forced alignment of spacecrafts prior to locking spacecrafts together pushes them apart and produces positive separation [19]. To avoid a disastrous collision during berthing between two spacecrafts, the brake in the docking mechanism is required to execute the braking of the chaser spacecraft. In addition, it is necessary to achieve the clutching operation in order that it can controllably release and separate two spacecrafts along a preselected separation axis [9]. When the machine is overloaded it results in failure of components such as shafts, burning of motors, and rupturing of gear teeth. The brake acts as an overload protector for safeguarding the docking mechanism.

As illustrated in Fig. 10(a), the friction pairs of the brake for docking mechanism consisted of friction discs made from powder metallurgy processed metalmatrix material and steel counterpart discs. $M$ and FS of this brake were demonstrated by testing in air, vacuum, low temperature vacuum, and in environmental cycling, as shown in Table 4. As can be seen, the brake could recover the stable frictional torque characteristics under different environments. Vibrations created by the brake are often harmful and classical torque ripple values of $15 \%$ of frictional torque were typically attained. The FS values exceeded 0.9 in different environments, indicating that the brake could steadily execute braking operation, clutching operations, and overload protection during the berthing and disconnecting between spacecrafts. This brake
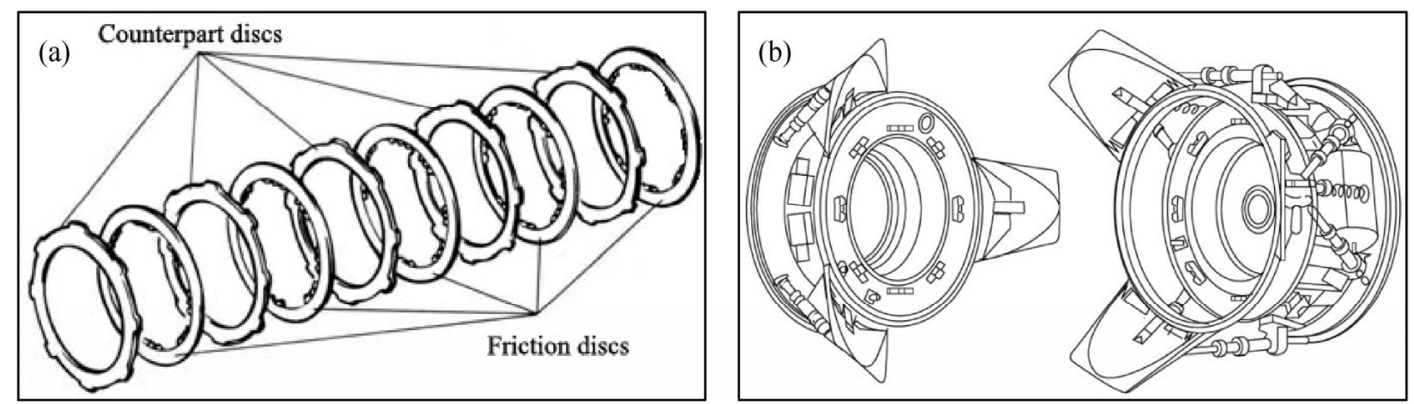

Fig. 10 Schematic view of (a) the friction pairs for (b) the docking mechanism. 
Table $4 \quad M$ and FS of the brake for docking mechanism under different conditions.

\begin{tabular}{|c|c|c|c|c|c|c|}
\hline \multirow[t]{2}{*}{ Types of operation } & \multicolumn{2}{|c|}{$\begin{array}{c}\text { In air at } 25^{\circ} \mathrm{C} \text { (before tribological } \\
\text { testing in vacuum) }\end{array}$} & \multicolumn{2}{|c|}{ In vacuum at $25^{\circ} \mathrm{C}$} & \multicolumn{2}{|c|}{ In vacuum at $-20^{\circ} \mathrm{C}$} \\
\hline & $M(\mathrm{~N} \cdot \mathrm{m})$ & FS & $M(\mathrm{~N} \cdot \mathrm{m})$ & FS & $M(\mathrm{~N} \cdot \mathrm{m})$ & FS \\
\hline Braking operation & $6.60-6.92$ & 0.979 & $6.63-7.19$ & 0.940 & $7.02-7.26$ & 0.980 \\
\hline Clutching operation & $6.62-7.01$ & 0.974 & $6.51-6.92$ & 0.973 & $6.66-6.97$ & 0.980 \\
\hline Overload protection & $37.57-42.34$ & 0.968 & $36.32-38.30$ & 0.973 & $38.63-39.76$ & 0.989 \\
\hline \multirow[t]{2}{*}{ Types of operation } & \multicolumn{2}{|c|}{ In vacuum at $-45^{\circ} \mathrm{C}$} & \multicolumn{2}{|c|}{ In vacuum at $75^{\circ} \mathrm{C}$} & \multicolumn{2}{|c|}{$\begin{array}{c}\text { In air at } 25^{\circ} \mathrm{C} \text { (after tribological } \\
\text { testing in vacuum) }\end{array}$} \\
\hline & $M(\mathrm{~N} \cdot \mathrm{m})$ & FS & $M(\mathrm{~N} \cdot \mathrm{m})$ & FS & $M(\mathrm{~N} \cdot \mathrm{m})$ & FS \\
\hline Braking operation & $6.88-7.38$ & 0.958 & $6.83-7.50$ & 0.934 & $6.73-6.88$ & 0.989 \\
\hline Clutching operation & $6.56-6.91$ & 0.975 & $7.02-7.43$ & 0.966 & $6.58-6.72$ & 0.989 \\
\hline Overload protection & $42.82-44.77$ & 0.980 & $38.77-41.02$ & 0.968 & $36.85-39.63$ & 0.973 \\
\hline
\end{tabular}

was successfully applied to the rendezvous and docking missions of "Shenzhou-8", "Shenzhou-9", "Shenzhou-10", "Shenzhou-11", and "Tianzhou-1" spacecrafts.

Fundamental studies on the properties of powder metallurgy processed metal-matrix materials under different conditions show that those materials could be of high interest for space related applications. Other potential space related applications for those materials include indexing mechanisms, robot arms, motor units, etc. Relevant work in those fields is also being conducted at Central South University.

\section{Conclusions}

Powder metallurgy processed metal-matrix friction materials hold great promise for space applications due to their outstanding comprehensive properties. In this paper, selected highlights of the study of the friction material at Central South University are presented. The important conclusions resulting from the above study as follows.

$\mathrm{Cu}-\mathrm{Sn}$ alloys were selected to be the matrix phase, which provided strength, high temperature stability, oxidation resistance, and high thermal conductivity. There was an equilibrium mass of lubricant and abrasives achieved by tailoring the contents of the friction and lubricant components, at which point the friction material exhibited the desired level of coefficient of friction and excellent frictional stability with less wear loss. Chemical compositions of the friction materials were obtained based on experimental studies.
In comparison with those in low vacuum, the friction material exhibited higher $\mu_{\text {mean }}$ and lower FS in air, however $\mu_{\text {mean }}$ was slightly lower and FS remained almost unchanged in high vacuum, and a significant increase in the wear rate in vacuum compared with that in air was observed. $\mu_{\text {mean }}$ significantly decreased whereas FS slightly increased with an increase in $P$. A slight increase in the wear rate was observed with increasing $P$ up to $0.048 \mathrm{MPa}$ after which a decreasing trend was observed. The friction material containing high contents of non-metallic ingredients can reduce the adhesion, cold-welding, and cold-shortness to a large extent. The wear mechanism was a complex mixture of oxidation, abrasive wear, and fatigue wear. No significant mass loss of the friction material was observed under different irradiations.

A powder metallurgy processed metal-matrix friction material was successfully applied to the docking mechanism of the "Shenzhou" mission. Relevant works in other potential space related applications such as indexing mechanism and robotic arms are being conducted by our group.

\section{Acknowledgement}

The authors acknowledge the National Natural Science Foundation of China (Nos. 51175516 and 51475476), the Fundamental Research Funds for the Central Universities of Central South University (No. 2014 zzts023) and Shanghai Key Laboratory of Spacecraft Mechanism (No. QT2010-081) of China for their financial supports. 
Open Access: The articles published in this journal are distributed under the terms of the Creative Commons Attribution 4.0 International License (http:// creativecommons.org/licenses/by/4.0/), which permits unrestricted use, distribution, and reproduction in any medium, provided you give appropriate credit to the original author(s) and the source, provide a link to the Creative Commons license, and indicate if changes were made.

\section{References}

[1] Roberts E W. Space tribology: its role in spacecraft mechanisms. J Phys D: Appl Phys 45: 1-17 (2012)

[2] Fan X Q, Xue Q J, Wang L P. Carbon-based solid-liquid lubricating coating for space applications-A review. Friction 3(3): 1-13 (2015)

[3] Jones W R, Jansen M J. Tribology for space applications. Proc Inst Mech Eng Part J 222(8): 997-1004 (2008)

[4] Voevodin A A, Zabinski J S. Nanocomposite and nanostructured tribological materials for space applictions. Compos Sci Technol 65(2): 741-748 (2005)

[5] Lv M, Zheng F, Wang Q H, Wang T M, Liang Y M. Friction and wear behaviors of carbon and aramid fibers reinforced polyimide composites in simulated space environment. Tribol Int 92: 246-254 (2015)

[6] Hawthorne H M, Kavanaugh J. The tribology of space mechanism friction brake materials. Canadian Aeronautics and Space Journal 36(2): 57-61 (1990)

[7] Baker F C, Favre E, Mozzon J M, Crausaz A, Jurients P. European robotic arm (ERA) manipulator joint system motor unit and tribological brake. Proc 8th European Symposium 438: 111-118 (1999)

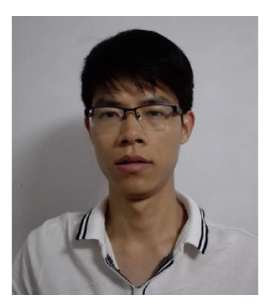

Yelong XIAO. He received his master degree in materials science and engineering in 2012 from Central South University, Changsha,

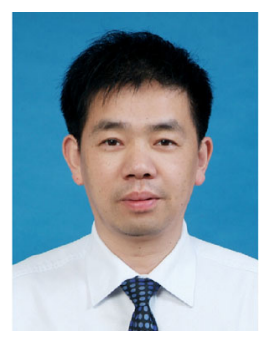

Pingping YAO. He received his master and Ph.D. degrees in materials science and engineering from Central South University, Changsha, China. He joined Powder Metallurgy Research Institute at Central South University from 1992. His current
[8] Yao P P, Xiao Y L, Deng J W. Study on space copper-based powder metallurgy friction material and its tribological properties. Adv Mater Res 284-286: 479-286 (2011)

[9] Xiao Y L, Yao P P, Zhou H B, Zhang Z Y, Gong T M, Zhao L, Zuo X T, Deng M W, Jin Z X. Friction and wear behavior of copper matrix composite for spacecraft rendezvous and docking under different conditions. Wear 320: 127-134 (2014)

[10] Yao P P, Xiao Y L, Zhou H B, Jin Z X. Tribological and mechanical properties of materials for friction pairs used to space docking. Adv Mater Res 538-541: 1929-1934 (2012)

[11] Asif M, Chandra K, Misra P S. Characterization of iron based hot powder brake pads for heavy duty applications. Int J Mech Mater Eng 8(2): 94-104 (2012)

[12] Xiong X, Chen J, Yao P P, Li S P, Huang B Y. Friction and wear behaviors and mechanisms of $\mathrm{Fe}$ and $\mathrm{SiO}_{2}$ in $\mathrm{Cu}$-based P/M friction materials. Wear 262: 1182-1186 (2007)

[13] Österle W, Dmitriev A I. The role of solid lubricants for brake friction materials. Lubricants 4(1): 1-22 (2016)

[14] Tjong S C, Lau K C. Tribological behaviour of SiC particlereinforced copper matrix composites. Mater Lett 43: 274-280 (2000)

[15] Kato H, Takama M, Iwai Y, Washida K, Sasaki Y. Wear and mechanical properties of sintered copper-tin composites containing graphite or molybdenum. Wear 1-6: 573-578 (2003)

[16] Bowden F P, Tabor D. The Friction and Lubrication of Solids, Part 2. Oxford (UK): Clarendon, 1964.

[17] Popov V L. Contact Mechanics and Friction, Physical Principles and Applications. Springer, 2010.

[18] Wigley D A. Materials for Low-temperature Use. Oxford (UK): Oxford University Press, 1978.

[19] Fehse W. Automated Rendezvous and Docking of Spacecraft. Cambridge (UK): Cambridge University Press, 2003.

China. He is currently a Ph.D. student at the same university. His research interests include the design, preparation, and characterization of metal matrix friction materials.

position is a professor, the supervisor of Ph.D. students. His research areas cover the friction materials, antifriction materials, and anti-wear materials, and their mechanical and tribological performances, and their applications in spacecraft, aircraft, high-speed trains and so on. 